\title{
The Application of Digital Media Technology in Art Design Field
}

\author{
Chuan Peng \\ The College of Post and Telecommunication of WIT, Wuhan, \\ Hubei, 430000, China
}

\begin{abstract}
With the rapid development of computer technology, the extensive application of digital media technology in art design field, it changed from the most primitive hand-painted production to the modern high-tech computer software to achieve the best results. The role of digital media technology has spread to all areas of the world.

This paper introduces the digital media software and technology commonly used in art. Take examples to describe the role of complementary software and a variety of features and uses of digital media technology in various art fields. Through a simple example to show the media digital software technology in environmental art and design, industrial design, visual communication design, animation and game design professional.
\end{abstract}

Keywords: digital media technology, computer aided, Digitizing, multimedia interaction

Digital media teaching is widely used in higher education, especially in the arts professional, such as environmental art and design, industrial modeling, visual communication, animation and so on. As a teaching art college teachers, these years have been in the digital media education research, digital media refers to the digital (binary form) text, graphics, images, animation, video, audio and other information media; to the modern network as the main carrier of transmission, with digital, network and multimedia features. With the development of modern science and technology, digital media technology is more and more widely used. Compared with multimedia, digital media emphasizes the characteristics of 
network communication and digitalization of information media. Digital media, as one of many art disciplines, has its unique teaching mode and learning method. In our traditional professional art learning, often theoretically dead books, techniques to imitate the teacher's circulation model. Even if the professional folk songs and listen to lectures are only a temporary change, back to the classroom Tao still not see any sense of innovation. Therefore, studio work, copying pictures, outdoor painting and art theory courses simply can not meet the creative needs of modern students.

Digital media technology mainly includes scene design, character image design, game program design, multimedia post-processing and human-computer interaction technology. Mainly for game development and Web site art and creative design work of such professional design. At present, the main courses in art undergraduate courses in China include: photography camera technology, the basis of art and design, digital media technology, programming design, database design, web design and production, interactive multimedia website development, digital signal processing, data Structure, algorithm design and analysis, objectoriented programming (java), computer graphics and image processing, humancomputer interaction technology, multimedia database, animation design and production, 3D modeling, TV program director and production, audio and video information processing, special effects production and Non-linear editing.

In the teaching of digital media technology in colleges and universities, there are many kinds of digital media courses in various art disciplines, including environmental art design, industrial modeling, visual communication, animation, game design, etc., but different for different majors. Teaching forms and methods of teaching practice.

Environmental art refers to the spatial planning of environmental art projects, the comprehensive plan of artistic conception plan, including environment and facilities planning, space and decoration plan, shape and structure plan, use function and aesthetic function plan. Environmental art, is an emerging, marginal, integrated art systems engineering, is an interdisciplinary integrated professional, involving art, sculpture, decorative culture, architectural knowledge, landscape art, ergonomics, design, materials, Psychology and other fields, regardless of the breadth of professional theory, or in the diversification of professional skills, have a certain representation. The art of environmental art focuses on the design and planning of three-dimensional space. In view of the characteristics of the specialty, the university offers the following courses: sketch, colour, architectural sketching, composition, surveying, interior drawing, renderings, photography, decorative structures and materials; Landscape design, landscape design, landscape design, plant configuration, model making, landscape planning and design, landscape design performance techniques, computer-aided design, landscape engineering, landscape architecture design, Introduction to Economics, Introduction to Management, Engineering Valuation, Furniture Design, Introduction to Environmental Art Design, Colour Composition, Stereoscopic Composition and Planar Composition. And digital media-related courses organic computer-aided design, landscape architecture design, environmental landscape design, I put them into the theory and practice of combining disciplines. They are 
used by the software, including: 3 Dmax, AutoCAD, Photoshop and so on. In 3D software, we should pay attention to the construction of the model, such as in 3Dmax, in the outdoor landscape, the professional use of polygon modeling and software modeling of the building, skilled use of software in the various views of the model editing The performance of the final effect is particularly important for the art of the environment, it relates to the structure of the model, material and light exposure location, range, colour and other factors. Now the most popular performance technology is the reality of the building materials with a map directly to the surface of the model, if you want to make it more realistic, the surface of the model generated bump texture, you can use 3Dmax plug-ins Unfold3D, Crazybump, xNormal , Etc., these software can help us to produce and the real environment as the performance effect. The effect of performance in the interior, the performance intensity is mainly concentrated in the space, material, light, rendering these points; 1 . Rational planning space needs to be used daily to learn the theoretical knowledge of interior design. 2. The use of the popular material we need to have a certain degree of market research experience. 3 . Lighting methods and techniques we need visual expression in the sense of the power of a certain design capability. 4 . Rendering realistic effects require us to be able to skillfully use commonly used software. Matching 3D plug-ins there are many, such as the optical network, VR renderer, Finalrender renderer, etc., can be used in indoor performance, and the effect is very good. And in building animation requirements are higher, in addition to the above-mentioned integrated indoor and outdoor performance methods, but also need animation professional knowledge, such as the use of the lens, animation, animation, character animation. For now, animation is the art of professional expression of the most advanced means, and the associated digital media software Premiere, Vegas and so on. Building animation process includes pre-data collection, two-dimensional threedimensional modeling, local animation rendering and the overall animation synthesis, post-production effects, which require us to have a sound digital media equipment, software and technology.

Industrial design originated in the aesthetic application of technology in the field of practice, is a combination of technology and the arts arising from a marginal discipline. Technology and art are interlinked, technology is biased to reason, art is perceptual and they are creative work. Generally speaking, technology mainly pursues functional beauty, and art mainly pursues formal beauty. Technology changes the material world of mankind, and art influences human emotions. Materiality and affection are also the two sides of human beings In the development of industrial society, the separation of technology and art leads to their disadvantages, such as the indifference of technology, dehumanization, the emotional bias of art. Modern industrial product design, is the application of engineering and artistic means to design, shape the image of the product, and its final unification in the product function, structure, technology, pleasantness, visual communication, market relations and achieved human Products) - a harmonious design of the environment. With the progress of the times, the development of science and technology, people's aesthetic concept of improvement has changed. There are many factors that affect product modeling, 
but now the product design, mainly emphasizing to meet the needs of people and the community, so nice generous and pleasant products for people's lives and production activities and improve the material and spiritual civilization of society as a whole. In digital media, China's colleges and universities set up a twodimensional computer graphics, three-dimensional computer graphics, twodimensional modeling design, three-dimensional modeling design courses. Is a focus on the practice of discipline, digital media technology used in industrial modeling is more common, the basic software 3Dmax, AutoCAD, Photoshop, Rhino and now relatively new surface modeling software Aliasstudio. Streamlined modeling has been pursued by industrial designers, the most suitable feature in the three-dimensional software is the Nurbs (surface) modeling, it is a very good modeling, which support the advanced three-dimensional software which modeling approach. NURBS can better control the curvature of the object surface than the traditional mesh modeling method, which can create a more realistic, vivid shape. Whether in the mainstream three-dimensional software 3Dmax, Maya, or in the industrial modeling iconic software Rhino, there are Nurbs. It is specifically designed for 3D modeling using a computer, and does not exist in the traditional cartographic domain. So we are now learning industrial design and industrial design people have a certain ratio conversion capacity and three-dimensional space and other basic, first, we will draw a product on paper drafts, and then the precise plan in the software rendering Complex 3D modeling (eg 3Dmax, Maya, Rhino, UG, SolidWorks, SolidEdge, MDT, Pro / E) can be performed after modeling the exact product dimensions. Adjust the nodes on the model surface to achieve contours and shapes using curves and surfaces. Modeling is only the beginning of our product design, if you want to design superior product results, then we must give the product to give the material and mechanism. The product model material is to be derived from real life, we will be in the form of high-resolution image acquisition will be applied to the computer software (such as Photoshop), the three-dimensional model of all patches expanded in a plane area, and then The acquired high-resolution image is tiled into the expanded planar area, and finally the flattened area is pasted back to the surface of the model. In the software for its virtual lighting, in many 3D software has a virtual light, the general form of lighting include indoor lighting, daylight, parallel light, point light, etc., they can simulate any real scene in the Light and shadow effects, the placement of the model by the designer, the light source and the direction of emission can be rendered in any situation under the model shape. (Such as AE, Combustion, DFsion, Shake, Premiere) and then image, special effects processing, for the model and then add some, such as light, fire, electricity, etc. can impact the visual senses (such as AE) The effect can produce a complete product results. Through the most advanced three-dimensional digital media technology for our industrial products, it can be more intuitive to show the product's appearance, performance, use and other aspects.

Visual communication design is the design of the use of graphic visual symbols - text, illustrations and signs, to pass to the recipient of a variety of information design. Its main function is to play the role of dissemination and promotion. Visual communication design industry is often referred to as graphic design, it 
involves a lot of areas, such as: newspapers, magazines, print ads on both sides of the road billboards, light boxes are all areas of visual communication design. In design, its content mainly includes: advertising design, printing design, book binding design, poster design, product packaging design, corporate image design (VI design), display design, digital image design. Graphic Design, Graphic Design, Graphic Basics, Introduction to Modern Art, Introduction to Modern Advertising Design, POP Advertising Sketch, Advertising Graphic Design, Graphic Advertising Image Design, Illustration Design, World Excellence Course Design, Sketch, Colour, Composition (VI) design, book binding design, packaging structure and decoration design, packaging design and packaging design, packaging design and packaging design, packaging design, packaging design, packaging design, packaging design, Graphic design software applications (Photoshop, Illustrator), Indesign layout applications, 3DS MAX three-dimensional performance, printing process. Photoshop is a professional in the use of more than digital media software, is mainly used to do image colour processing. Font design, poster product packaging design, corporate image design (VI design), display design, the general is the use of vector graphics software Illustrator. First of all, in Illustrator will design a good logo, font and other prototype drawn well, and then into the Photoshop post-synthesis, colour processing, typesetting and so on. Today's visual communication design is not stuck in the static image, and requires a stronger visual impact, so dynamic video effects also into the professional to. Commonly used in video advertising effects software after effects, vegas, illution, etc., these software can produce such as water, fire, electricity and other special effects to. Take After Effects example, if you want to do something similar to the effect of fireworks, first in the software to create a particle emitter, adjust the particle emitter position, number, size, select the particle layer, Find the effect of a glow given to the layer, so that we can create a fireworks effect. If you want to do some branding of dynamic audio and video, you can choose to combine Illustrator and Flash, you can first Illustrator do I need to use vector material (fonts, logos, roles, scenes, etc.), because the two software is A company developed, so we do not have to worry about the software between each other down objects, you can directly produced in Illustrator good file into the Flash in the dynamic production. For some simple graphics and graphics animation deformation of Flash can be fully met. If you encounter a complex two-dimensional role of dynamic production, then you have to spend some effort, first of all we have to make a good role in Illustrator each need to move the joint parts into Flash for component classification, and then combined in different layers, so that We can be carried out in an orderly manner the dynamic production of the parts, for vector software, the colour part of the works can be tested on the colour appears monotonous, we can use Photoshop rich colours, this can make the work considerably.

Animation is an independent integrated art disciplines, in China is a new discipline, the industry called the sunrise industry. The subject mainly cultivates the basic knowledge and theory needed for animation, film, TV and creation, and can be engaged in animated original painting, animated creative design and editing and $3 \mathrm{D}$ computer animation creation theory in animation, film and 
television production positions. The main courses are film and television drama, film and television sound, animation techniques, film and television animation, multimedia technology and applications, animation design, animation director. The main practical teaching links: including sketch, sketches, character design, scene design, card Man design and creation, animation colour, animation dubbing, animated short film shooting. 2D animation software including: ANIMO, RETAS PRO, USANIMATION, 3D animation software include: 3DMAX, MAYA, LIGHTWAVE, web animation software, including: FLASH. Now the computergenerated two-dimensional animation is an improvement of the traditional manual animation, by entering and editing key frames; calculation and generation of intermediate frames; definition and display motion path; interactive to the screen colour; produce some special effects; Synchronization with the sound; control campaign series of records and so on. Two-dimensional animation software more classic Ulead's GIF Animator software and Adobe's Photoshop and Flash software, the main production methods in two ways: First, frame-byframe drawing of a single action picture, through the digital media software will These drawn pictures link up to form a continuous dynamic picture, but the way belongs to the traditional animation production and heavy workload, making a 60 seconds or so animation often requires 1500 pictures. Second, according to the law of motion of things, will need to separate the part of the independent, first from the local animation to start production, and finally integrated into a complete animation, but the way the dynamic description of things relatively rough, can only produce a simple animation, Generally widely used in online media. Contemporary 3D media technology is the primary means of producing realistic animations. 3D animation software: 3Dmax, Maya, softimage, 3Dstudio and so on. Three-dimensional animation is entirely in the simulation environment provided by the computer three-dimensional design software, through the software function design role and scene modeling, to create and reality similar to the three-dimensional objects, and give the relevant properties, through the computer in accordance with the relevant design parameters The simulation rendering, and ultimately the formation of smooth animation screen. Computer three-dimensional technology is a combination of modern animation technology and art, it is a concentrated expression of high-tech, image and simulation and other scientific integration, full of animation to the imagination of the space. Creators create realism and virtuality by constructing models, rendering materials, defining lights, animating, adding effects and effects, and any imagery. In addition, the three-dimensional animation technology, high flexibility, convenience has been highly praised and recognized animation, compared with the traditional hand-drawn animation, three-dimensional animation to achieve a high level of leap. From the animation aspect, the three-dimensional animation technology will be the liberation of the traditional human resources and only the relevant technical staff to carry out computer operations can be achieved, the production costs with the extension of the production story gradually reduced, but also reduces the animation Threshold, amateur animation enthusiasts to provide the performance stage. Animation technology will gradually reduce the difficulty, which is conducive to the promotion of animation and animation industry's rapid 
development. Three-dimensional animation involved in the field are: construction, planning, 3D animation, landscape, product demonstrations, simulation animation, titles animation, advertising animation, film and television animation, character animation. Character animation, for example, the role of animation related to: 3D game character animation, movie character animation, advertising character animation, character animation. Computer role animation is generally completed by the following steps: 1 . According to the creative script for the sub-lens, draw the screen sub-lens movement, pave the way for three-dimensional production (on behalf of digital media software Photoshop, painter, etc.); 3D models, 3D scenes, 3D props model in the three-dimensional (3Dmax), 3D models, 3D models, 3D models, Software, the model of precision production; 5. According to the script design of the 3D model, we do the colour, texture and other settings (on behalf of digital media software Unfold3D, Crazybump, xNormal); 6. According to the storyline analysis, (7) According to the lens of the storyboard and the time to the role or other objects need to be active to produce a performance animation for each shot; 8 . The animation scene (mainly for the role) to the animation of some of the action settings; Background music, sound effects, subtitles and animation one by one match the synthesis, and ultimately into the complete role of the animation (on behalf of the software has After-effects, combustion, etc.); 10 will be dubbing, background music, Film production (on behalf of digital media software Audition, Vegas, LogicAudio, Samplitude, sonar, SoundForge, Wavelab).

Game design is derived from the animation of a category, it is necessary to use the media software is almost the same as making the role of animation, but it requires knowledge related to the computer programming. In the game production is mainly divided into two blocks: First, the art part; including the game scene, the role of the game, the game props, animation and other parts of the game character animation. Second, the program part; the main development is the game platform, engine (on behalf of the software Flash, D3d, Java, C + +, etc.). I have done in the post-graduate game-related actions, engaged in the work of artists, where I have some experience in the game development process, I think the art teacher is a very important part, because the produced Things are intuitive to show in front of the audience, so whether it is in the shape or in the model of the map and the action settings need to use their brains, maps in these areas is particularly important, it reflects your game quality is not high Key, the current game mapping technology is no longer a simple Photoshop painting a picture so simple, it needs more texture, the mechanism of integration, this will make our model more realistic effect, of course, in exchange for the cost is equipped with high configuration Of the host computer. Generally used to do the mapping software Unfold3D, Crazybump, xNormal, they can produce high-quality effects to the model.

With the development of digital media technology, digital media technology update will be accelerated. How to adapt to the rapid development of digital media software, there are a lot of knowledge to learn, and constantly improve ourselves, master and application are the quality and ability our designer should have. 


\section{References}

[1] Peng Peng Digital Media Art Design Personnel Training and Textbook Construction "Art Review", 2010 (4): 104-105

[2] Jiang Junjun. The Influence of Digital Media on Environmental Art Design "Young Reporter", 2016 (20): 132-133

[3] Yang Hong Analysis on the Presentation of Digital Media Art "Film Review", 2010, 2010 (3): 80-81

[4] A New Change in the Development of Art Education in the Art and Design Major of Engineering Majors - A Talk on the Teaching of Art Design in Beijing Jiaotong University 2009 (6): 46-53

[5] Jing Dong, Yi Long Innovative Digital Media Talents Training and Technology Courses "Continuing Education Research", 2012 (1): 159-161

[6] Xia Guangfu, Hua Yixiong. The Influence of Digital Media Art on Contemporary Design Education "Journalism", 2006 (2): 128-128 